
\title{
25 Research Suare \\ Effects Of Nitric Acid And Sulfuric Acid On Thermal Stability Of Nitrocellulose
}

\author{
Qi Sun ( $\nabla$ skdsunqi@163.com ) \\ Ningbo University https://orcid.org/0000-0002-6198-7836 \\ Yue Qiu \\ Ningbo University \\ wenjun Xu \\ Ningbo University
}

\section{Research Article}

Keywords: Nitrocellulose, thermal decomposition, impurity, mechanism

Posted Date: February 16th, 2022

DOI: https://doi.org/10.21203/rs.3.rs-1322929/v1

License: (c) (1) This work is licensed under a Creative Commons Attribution 4.0 International License.

Read Full License 

China.

\section{Abstract}

6 Sulfuric acid and nitric acid are two typical impurities in manufacturing, storage, 7 processing, and transportation of nitrocellulose, and may reduce the thermal stability of

8 nitrocellulose and increase hazards. Thermal behaviors of nitrocellulose contaminated

9 by nitric acid and sulfuric acid were explored by a C80 micro calorimeter. Two 10 exothermic processes were observed after adding acids into nitrocellulose. Kinetics and 11 thermodynamics of pure nitrocellulose and its mixture with two acids were obtained by 12 Kissinger method and Ozawa method. The catalytic mechanism was tested by analysis 13 of reaction curve and isothermal experiments. Impurities of nitric acid and sulfuric acid 14 decreased thermal stability of nitrocellulose with different mechanisms.

15 Keywords: Nitrocellulose; thermal decomposition; impurity; mechanism 

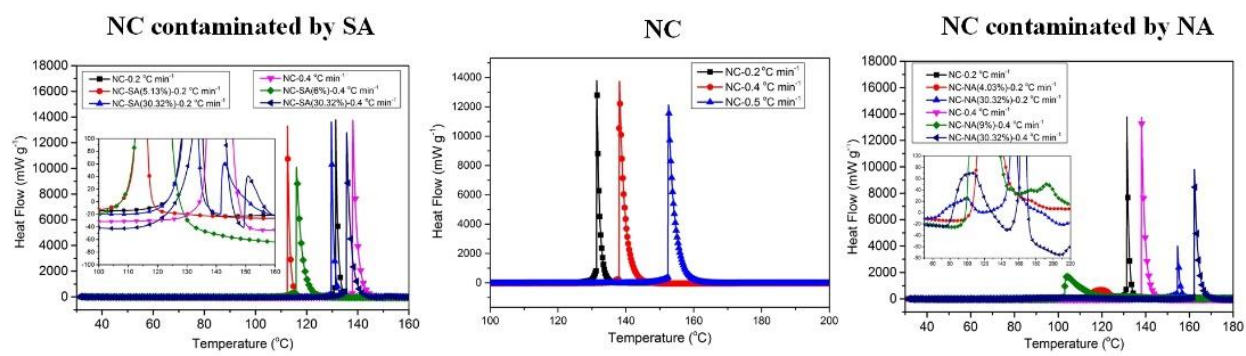

Heat flow plots from room temperature to $300{ }^{\circ} \mathrm{C}$
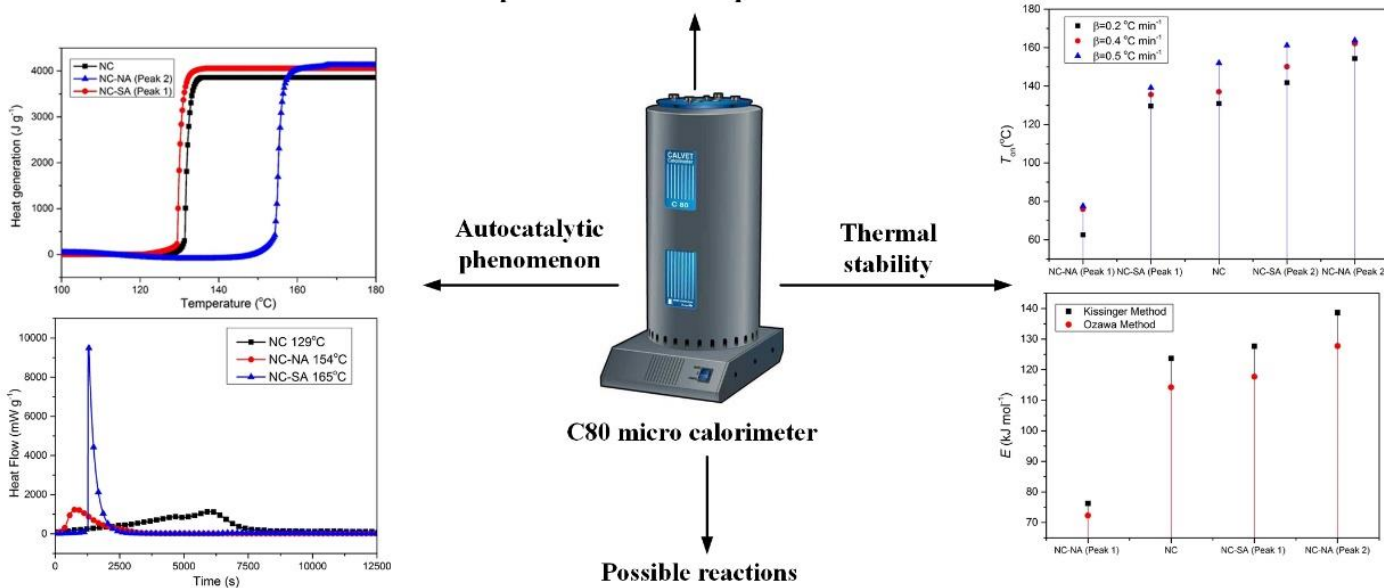

Thermal decomposition of nitric acid Thermal decomposition of nitrocellulose

$4 \mathrm{HNO}_{3} \rightleftharpoons 2 \mathrm{H}_{2} \mathrm{O}+4 \mathrm{NO}_{2}+\mathrm{O}_{2}$

$\mathrm{R}-\mathrm{ONO}_{2} \rightarrow \mathrm{RO} \cdot+\mathrm{NO}_{2}$

$2 \mathrm{NO}_{2} \rightleftharpoons \mathrm{N}_{2} \mathrm{O}_{4}$

$\mathrm{RO} \cdot+\mathrm{NO}_{2} \rightarrow \mathrm{ROO} \cdot+\mathrm{NO}$

$\mathrm{H}_{2} \mathrm{SO}_{4} \rightarrow \mathrm{H}_{2} \mathrm{O}+\mathrm{SO}_{3}$

$\mathrm{ROO} \cdot+\mathrm{NO} \cdot \rightarrow \mathrm{RO} \cdot+\mathrm{NO}_{2} \cdot\left(\right.$ or $\left.\mathrm{RONO}_{2}\right)$

Acid hydrolysis of nitrocellulose

$\mathrm{H}_{2} \mathrm{O} \rightleftharpoons \mathrm{H}^{+}+\mathrm{OH}^{-}$

Hydrolysis of NC

Formation of sulfuric acid ester

$\mathrm{RONO}_{2}+\mathrm{H}^{+} \rightleftharpoons \mathrm{RONO}_{2} \mathrm{H}^{+}$

$\mathrm{H}_{2} \mathrm{O} \rightleftharpoons \mathrm{H}^{+}+\mathrm{OH}^{-}$

$\mathrm{R}-\mathrm{ONO}_{2}+\mathrm{SO}_{3} \rightarrow \mathrm{R}-\mathrm{OSO}_{3}+\mathrm{NO}_{2}$

$\mathrm{RONO}_{2} \mathrm{H}^{+} \rightarrow \mathrm{ROH}+\mathrm{NO}_{2}^{+}$

$\mathrm{NO}_{2}^{+}+\mathrm{OH}^{-} \rightarrow \mathrm{HNO}_{3}$

$\mathrm{RONO}_{2}+\mathrm{OH}^{-} \rightarrow \mathrm{ROH}+\mathrm{NO}_{3}^{-}$

$\mathrm{RCH}_{2} \mathrm{ONO}_{2}+\mathrm{OH}^{-} \rightarrow \mathrm{RC}(\mathrm{O}) \mathrm{H}+\mathrm{H}_{2} \mathrm{O}+\mathrm{NO}_{2}^{-}$

\section{Introduction}

Nitrocellulose (NC) is a derivative nitro compound obtained by esterification reaction between natural cellulose $\left(\left[\mathrm{C}_{6} \mathrm{H}_{7} \mathrm{O}_{2}(\mathrm{OH})_{3}\right]_{\mathrm{n}}\right)$ and nitric acid (NA) [1], in which part of the hydroxyl groups $(-\mathrm{OH})$ in cellulose are esterified into nitrate ester groups ($\mathrm{ONO}_{2}$ ) [1]. Due to these groups, $\mathrm{NC}$ is an energetic material. And yet it is widely used in manufacturing of lacquers, photographic film, printing inks, celluloid, and explosives [2]. NC is stable in room temperature but could easily auto-ignite under high temperature accompanying by rapid decomposition [3]. Many accidents were caused by the spontaneous ignition of $\mathrm{NC}$, and a typical example is the $8 \bullet 12$ fire and explosion accidents occurred in Tianjin Port, China. Besides, in the process of manufacturing, storage, transportation and practical use, NC is likely to be contaminated by impurities, 
such as inorganic acids, organic oil and so on. Contamination of pure chemicals, especially nitro compounds contaminated by impurities may greatly lower the stability, leading to unexpected decomposition and thermal hazards [4].

Previous research has done many works according to the thermal decomposition phenomenon, kinetics, and mechanism of NC. It is generally accepted that decomposition of $\mathrm{NC}$ begins by the break of $-\mathrm{O}-\mathrm{NO}_{2}$ and release $\mathrm{NO}_{2}$ gaseous products which have catalytic effects on the decomposition process [5-7]. However, there have been very few works to explore the effects of acid impurities on thermal behavior of NC. The only accessible work of these authors is carried out by Katoh et al. [8], who applied an ARC (Accelerating Rate Calorimeter) technique to detect the influences of sulfuric acid (SA) on thermal behavior of NC. Their experiments showed that the existence of SA obviously reduced the onset temperature of decomposition and cause rapid explosion [8]. In addition to SA, NA is also a typical impurity in industry. However, there is a blank in comparison of these two impurities in perspective of mechanism, kinetics, and thermodynamics. Hence, a micro calorimeter technique is applied in this study to obtain the thermal behavior of NC contaminated by NA and SA, respectively. The different effects of two acids on thermal stability of NC are compared. The kinetics and thermodynamics are calculated, and the mechanism and hazards are identified.

\section{Samples and experiment}

\subsection{Samples preparation}

The experimental samples are coating used nitrocellulose. An Elementar varlo EL produced by Elementar Analysensysteme GmbH (Germany) was applied to determine the nitrogen content, which is $11.76 \% \pm 0.03 \%$. NA and SA in concentration of $20 \%$ were made in laboratory by diluting distilled water into concentrated acids of AR grade. The mass fraction of two acids added in mixture is about $30.32 \%$. Detailed information of all samples is listed in Table 1. 
Table 1. Information of experimental samples.

\begin{tabular}{cccc}
\hline Sample No. & Sample composition & NC mass $/ \mathrm{mg}$ & Total mass $/ \mathrm{mg}$ \\
\hline NC & $100 \% \mathrm{NC}$ & 125.9 & 125.9 \\
NC-NA & $30.32 \% \mathrm{NA}, 69.68 \% \mathrm{NC}$ & 128.7 & 215.7 \\
NC-SA & $30.32 \% \mathrm{SA}, 69.68 \% \mathrm{NC}$ & 150.3 & 184.7 \\
\hline
\end{tabular}

\subsection{Experimental apparatus and program}

A calvet heat flux calorimeter (C80) manufactured by SETARAM (France) was applied to detect the thermal behavior. It has major merits of high sensitivity with several $\mu \mathrm{W}$ at least and could contain high pressure and large sample mass. Samples were heated from room temperature to $300{ }^{\circ} \mathrm{C}$ at heating rates of $0.2,0.4$ and $0.5{ }^{\circ} \mathrm{C}$ $\min ^{-1}$, respectively. All the isothermal experiments were set to last for $15000 \mathrm{~s}$. The sample was sealed in the reaction cell, and reference cell was filled with alumina in the same mass. During all experimental process, normal air atmosphere was applied.

\section{Results and discussion}

\subsection{Effects of acids and heating rate on thermal behavior}

Heat flow plots of three samples under heating rates of $0.2,0.4$ and $0.5{ }^{\circ} \mathrm{C} \mathrm{min}-1$ by C80 micro calorimeter are shown in Fig. 1 (a) (c). Fig. 1 (d) compares the heat flow plots of three samples under a $0.2^{\circ} \mathrm{C} \mathrm{min}^{-1}$ heating rate. Based on previous experiences [9], the heat flow plots are analyzed by parameters include onset temperature $\left(T_{\mathrm{on}}\right)$, peak temperature $\left(T_{\mathrm{m}}\right)$, and peak heat flow $\left(H_{\mathrm{m}}\right)$ and so on. Onset temperatures is extrapolated as the temperature at intersection of baseline and tangent to the exothermic peak [10]. Information of the plots in details are listed in Table 2 4. 

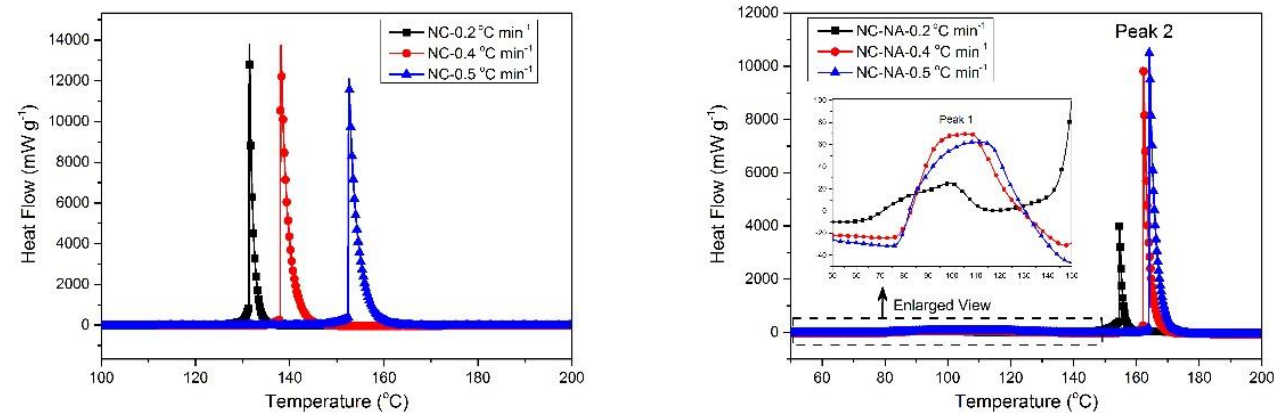

75

76

77

78

79

80

81

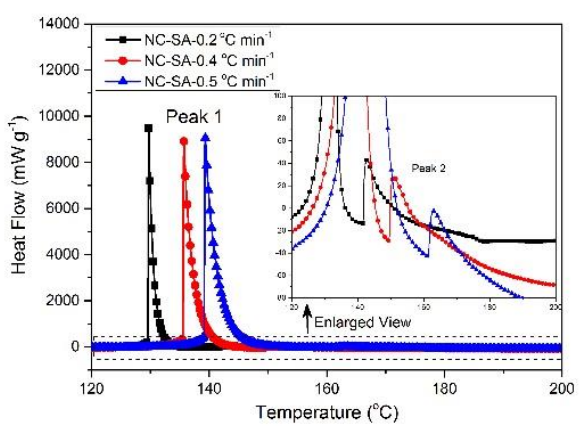

Fig. 1. Heat flow plots of (a) NC, (b) NC mixed with NA, (c) NC mixed with SA under heating rates of $0.2,0.4,0.5{ }^{\circ} \mathrm{C} \mathrm{min}{ }^{-1}$.

Table 2. Heat flow characteristics of $\mathrm{NC}$ under heating rate of $0.2,0.4,0.5^{\circ} \mathrm{C}$ $\min ^{-1}$.

\begin{tabular}{ccccccc}
\hline No. & $T_{\text {on }}\left({ }^{\circ} \mathrm{C}\right)$ & $\triangle T\left({ }^{\circ} \mathrm{C}\right)$ & $H_{\mathrm{m}}\left(\mathrm{mW} \mathrm{g}^{-1}\right)$ & $T_{\mathrm{m}}\left({ }^{\circ} \mathrm{C}\right)$ & $\triangle T_{\mathrm{m}}\left({ }^{\circ} \mathrm{C}\right)$ & $\triangle H\left(\mathrm{~J} \mathrm{~g}^{-1}\right)$ \\
\hline NC-0.2 & 142.94 & 3.0 & 14669.65 & 143.04 & 0.02 & 3799.04 \\
$\mathrm{NC}-0.4$ & 138.09 & 4.02 & 13735.66 & 138.15 & 0.06 & 3620.617 \\
$\mathrm{NC}-0.5$ & 152.47 & 4.41 & 12124.86 & 152.56 & 0.11 & 3131.186 \\
\hline
\end{tabular}

Table 3. Heat flow characteristics (Peak 1) of NC mixed with acids under heating rates of $0.2,0.4,0.5^{\circ} \mathrm{C} \mathrm{min}^{-1}$.

\begin{tabular}{ccccccc}
\hline No. & $T_{\text {on }}\left({ }^{\circ} \mathrm{C}\right)$ & $\triangle T\left({ }^{\circ} \mathrm{C}\right)$ & $H_{\mathrm{m}}\left(\mathrm{mW} \mathrm{g}^{-1}\right)$ & $T_{\mathrm{m}}\left({ }^{\circ} \mathrm{C}\right)$ & $\triangle T_{\mathrm{m}}\left({ }^{\circ} \mathrm{C}\right)$ & $\triangle H\left(\mathrm{~J} \mathrm{~g}^{-1}\right)$ \\
\hline NC-NA-0.2 & 62.53 & 57.92 & 25.12 & 99.48 & 36.95 & 504.21 \\
NC-NA-0.4 & 75.9 & 79.27 & 59.84 & 106.52 & 30.62 & 1019.40 \\
NC-NA-0.5 & 77.6 & 71.7 & 62.31 & 112.89 & 35.29 & 880.51 \\
NC-SA-0.2 & 124.35 & 12.67 & 9491.64 & 129.72 & 5.37 & 4058.09 \\
NC-SA-0.4 & 126.02 & 21.7 & 8908 & 135.71 & 9.69 & 3696.63 \\
\hline
\end{tabular}




$\begin{array}{lllllll}\text { NC-SA-0.5 } & 131.22 & 24.35 & 9058.92 & 139.34 & 8.12 & 3854.48\end{array}$

82

83

84

\begin{tabular}{ccccccc}
\hline No. & $T_{\text {on }}\left({ }^{\circ} \mathrm{C}\right)$ & $\triangle T\left({ }^{\circ} \mathrm{C}\right)$ & $H_{\mathrm{m}}\left(\mathrm{mW} \mathrm{g}^{-1}\right)$ & $T_{\mathrm{m}}\left({ }^{\circ} \mathrm{C}\right)$ & $\triangle T_{\mathrm{m}}\left({ }^{\circ} \mathrm{C}\right)$ & $\triangle H\left(\mathrm{~J} \mathrm{~g}^{-1}\right)$ \\
\hline NC-NA-0.2 & 141.83 & 21.74 & 3986.84 & 154.6 & 12.77 & 3125.76 \\
NC-NA-0.4 & 153.12 & 18.74 & 9812.83 & 162.34 & 9.22 & 3887.69 \\
NC-NA-0.5 & 156.67 & 20.14 & 10684.35 & 164.17 & 7.5 & 3986.68 \\
NC-SA-0.2 & 141.75 & 36.06 & 43.13 & 142.72 & 0.97 & 288.39 \\
NC-SA-0.4 & 150.07 & 43.54 & 28.76 & 150.73 & 0.66 & 238.56 \\
NC-SA-0.5 & 161.17 & 31.17 & -2.36 & 162.94 & 1.77 & 146.29 \\
\hline
\end{tabular}

Table 4. Heat flow characteristics (Peak 2) of NC mixed with acids under heating rates of $0.2,0.4,0.5{ }^{\circ} \mathrm{C} \mathrm{min}^{-1}$.
85

Heated from room temperature to $300{ }^{\circ} \mathrm{C}$, one exothermic peak was observed in NC. The temperate region was $162 \sim 182{ }^{\circ} \mathrm{C}$, with a peak heat flow of $981.42 \mathrm{~mW} \mathrm{~g}^{-1}$ at temperature of $176^{\circ} \mathrm{C}$. From Fig. 1 (b) and (c), two peaks were identified under three heating rates, noted as Peak 1, B for NC mixed with NA and Peak 1', B' for NC mixed with SA. For NC mixed with NA, the first exothermic process ranged from $62.53{ }^{\circ} \mathrm{C}$ to $120.45^{\circ} \mathrm{C}$, with peak heat flow of $25.12 \mathrm{~mW} \mathrm{~g}^{-1}$. Then a much sharper exothermic peak was shown (Peak 2). The initial temperature of Peak 2 moved forward to $141.53{ }^{\circ} \mathrm{C}$, and quickly ended at $163.57^{\circ} \mathrm{C}$. The thermal decomposition process of Peak 2 proceeded more rapidly than sample 1 and reached $H_{\mathrm{m}}$ of $3986.84 \mathrm{~mW} \mathrm{~g}^{-1}$ at temperature of $154.6{ }^{\circ} \mathrm{C}$. The value of $H_{\mathrm{m}}$ is four times higher than NC. After $154{ }^{\circ} \mathrm{C}$, there were some variations in the heat flow curves, but were insignificant comparing with the $\mathrm{H}_{\mathrm{m}}$. The Peak 1 of NC mixed with NA was very slight and insignificant compared to Peak 2. While for NC mixed with SA, Peak 1' contributed to most of the heat and Peak 2' was very small. NC mixed with SA had the sharpest exothermic peak started at $124.35^{\circ} \mathrm{C}$ and promptly reached the highest $H_{\mathrm{m}}$ of $9491.64 \mathrm{~mW} \mathrm{~g}^{-1}$ at 129.72 ${ }^{\circ} \mathrm{C}$, over twice higher than the value of $\mathrm{NC}$ mixed with NA. Its temperature region for thermal decomposition of Peak 1' ended at $137.02{ }^{\circ} \mathrm{C}$. The onset temperature was 
103 dramatically lower than other samples, and it took much shorter time to reach the peak 104 heat flow. After Peak 1', a secondary Peak 2' was identified from 141.75 to $177.81{ }^{\circ} \mathrm{C}$, 105 which also reached its Peak 1 at $142.72{ }^{\circ} \mathrm{C}$ rapidly.

106 With increase of heating rate, all the heat flow plots moved to a high temperature, 107 and there was an obvious change of $T_{\mathrm{m}}$ and $H_{\mathrm{m}}$ for $\mathrm{NC}$ and Peak 2 of NC mixed with 108 NA. The Peak 2 became much sharper and narrower. For the Peak 1' in NC mixed with $109 \mathrm{SA}, T_{\text {on }}$ became higher but $T_{\mathrm{m}}$ and $H_{\mathrm{m}}$ were similar, almost reaching the measuring range 110 of the experimental apparatus under three heating rates, indicating a more vigorous 111 exothermic process. The phenomenon of moving towards higher temperature region is 112 caused by the thermos inertia, referring to a relative lag of temperature between samples 113 and apparatus [11]. With a higher heating rate, temperature of samples cannot catch up 114 with furnace temperature, leading to a lag of heat flow plots. So a higher onset 115 temperature and peak temperature were achieved. However, the heat flow plots were in similar shape under various heating rates, indicating that heating rate did not change 117 the reaction mechanism. Therefore, the kinetics, thermodynamics, reaction mechanism 118 and thermal hazards identified under one heating rate could represent the characteristics 119 of samples in general. To obtain more reliable results, the analysis and calculation in 120 the following content will be carried out based on the data obtained by a $0.2{ }^{\circ} \mathrm{C} \mathrm{min}-1$ 121 heating rate.

122 The changes of heat generation by per mass sample versus temperature are shown 123 in Fig. 2. Adding NA and SA greatly reduced the onset temperature for thermal 124 decomposition and narrowed the temperature region (or time region) for decomposition 125 reactions. However, two acids had different effects on the heat generation. The heat 126 generation by pure $\mathrm{NC}$ was close to $4000 \mathrm{~J} \mathrm{~g}^{-1}$. After adding NA, the heat generation 127 was lower than $2000 \mathrm{~J} \mathrm{~g}^{-1}$, reduced by $30 \%$ when comparing with pure NC. While add 128 of SA improved the heat generation to outnumber $4000 \mathrm{~J} \mathrm{~g}^{-1}$, higher than the value of 129 pure NC. 


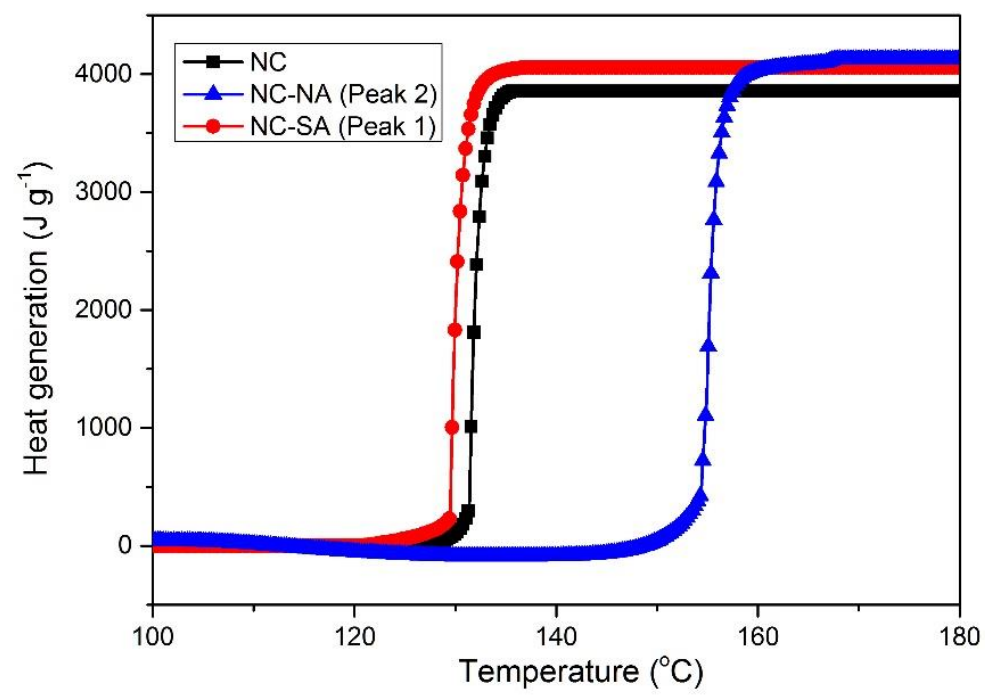

131 Fig. 2. Comparison of per mass heat generation of three samples under a $0.2^{\circ} \mathrm{C}$ $\min ^{-1}$ heating rate. In summary, impurity of NA and SA both reduce the thermal stability of NC, and

134 lead to a more dramatic exothermic behavior within shorter time region. The influences 135 of two acids on thermal stability of NC could be concluded as follows. In perspective 136 of onset temperature, the thermal stability order of three samples is, pure $\mathrm{NC}>\mathrm{NC}$ with 137 NA impurity $>\mathrm{NC}$ with SA impurity. According to maximum heat flow, the order is NC 138 with SA impurity $>$ NC with NA impurity $>$ NC. For the dramatic extent of reaction 139 (expressed by temperature region of exothermic reaction), the order is $\mathrm{NC}>\mathrm{NC}$ with 140 NA impurity $>$ NC with SA impurity. And for the heat of reaction, the order is NC with 141 SA impurity $>\mathrm{NC}>\mathrm{NC}$ with NA impurity.

\subsection{Autocatalytic mechanism analysis}

143 Two methods are applied in this study to explore the autocatalytic reaction 144 mechanism of these samples. The first method is to analyze the reaction profile. 145 Reaction profile could to some extent indicate the autocatalytic mechanism. The relation between heat generation and temperature reflects the conversion rate of sample

147 during reaction, and thus indicates possible mechanism by the reaction profile [12]. 148 From Fig. 2, despite the differences in onset temperature and heat generation, there is a 
similar pattern in changes of conversion rate over temperature. A sigmoidal model is reflected in three samples, representing autocatalytic thermal decomposition mechanism. The typical characteristic of sigmoidal model is that the initial and final stage demonstrate accelerating and decelerating behavior respectively, and the maximum reaction rate is achieved at a specific conversion rate during decomposition [12].

As Fig. 2 is obtained by heating samples under a constant rate, the reaction rate could change and influence reaction profiles. Therefore, three isothermal experiments were operated to prove the autocatalytic mechanisms. Isothermal heating method is a reliable way to detect and describe autocatalytic reaction. When the heat flow plot is in a shape of bell curve during isothermal condition, thermal decomposition of the chemical is an autocatalytic process $[13,14]$. In this study, the temperatures were set close to the onset temperature of Peak 2 and Peak 1' for NC mixed with NA and 3, respectively. This is because these two peaks played major role in the entire exothermic process. Heat flow plots of three experiments are shown in Fig. 3.

Consisting with the reaction profile in Fig. 2, isothermal experiments also proved the autocatalytic reaction mechanism based on the bell curve. The reaction heats calculated from isothermal experiments are given in Table 5. The values of NC and 3 were close to the reaction heat obtained by constant heating experiments, indicating that the thermal decomposition process nearly completed during isothermal heating process. For NC mixed with NA, the reaction heat in isothermal experiment covered $70.80 \%$ of total heat during constant heating condition, indicating that Peak 1 in NC mixed with NA could generate over $29 \%$ of the heat and the reaction heat of Peak 2 ' in NC mixed with SA could be ignored. Moreover, Fig. 3 also indicated the obvious differences in thermal stability of three samples. Although they all followed autocatalysis mechanism, NC mixed with SA had the sharpest reaction curve with highest heat flow among three samples. The curves of $\mathrm{NC}$ and 2 were in a nearly symmetrical bell shape. But NC mixed with SA had a very sharp Peak $1 \mathrm{fter}$ started to release heat. It also took longest time for NC to reached exothermic peak. It is assumed that, adding acids changed the thermal decomposition process of $\mathrm{NC}$ by activating 
179 intermediate products generated from NC decomposition. And this activation occurred 180 before $\mathrm{NC}$ reached the maximum decomposition rate.

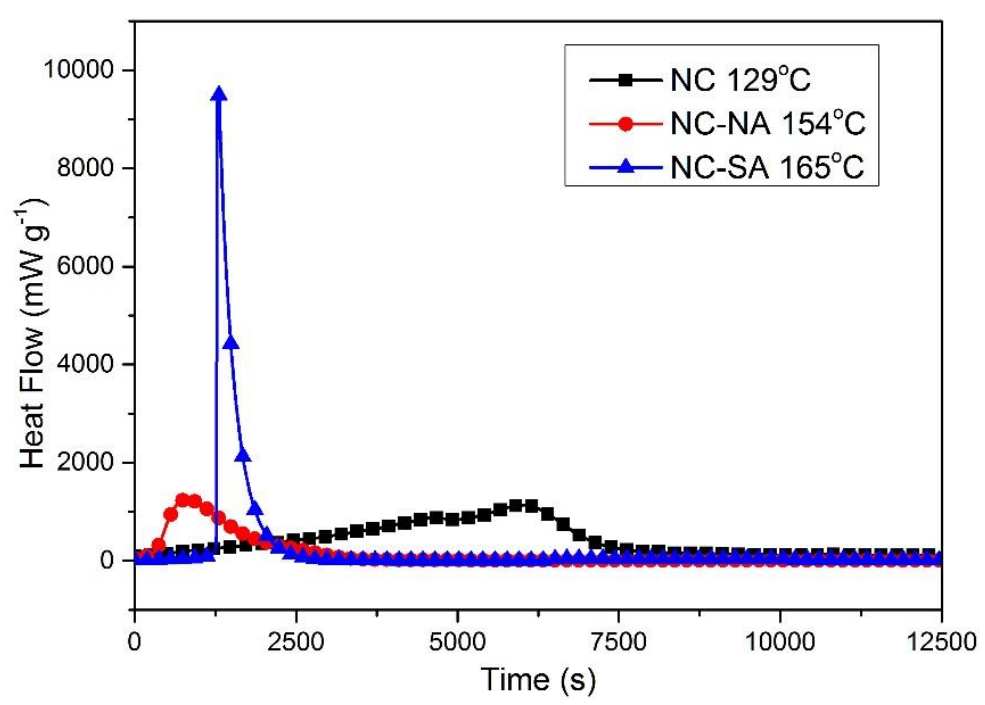

Fig. 3. Isothermal experimental results of three samples.

Table 5. Comparison of reaction heat in isothermal and constant heating experiments for three samples under a $0.2 \mathrm{~min}^{-1}$ heating rate.

\begin{tabular}{cccc}
\hline No. & $\triangle H_{\text {iso }}\left(\mathrm{J} \mathrm{g}^{-1}\right)$ & $\triangle H\left(\mathrm{~J} \mathrm{~g}^{-1}\right)$ & Proportions $(\%)$ \\
\hline NC & 3857.95 & 3865.065 & $99.81 \%$ \\
NC-NA & 2212.89 & 3125.763 & $70.80 \%$ \\
NC-SA & 3904.29 & 4058.088 & $96.21 \%$ \\
\hline
\end{tabular}

\subsection{Calculation of kinetics and thermodynamics}

To solve the kinetics and thermodynamics, the Arrhenius law is assumed. Model

188 free kinetics under various heating rates is an advanced principle to solve the parameters.

189 Based on the fundamental thermal decomposition function of $\mathrm{d} \alpha / \mathrm{d} t=k(\mathrm{~T}) f(\alpha)$, model

190 free methods could obtain activation energy without assumption of reaction model, and 191 thus avoid errors caused by selecting wrong model. A typical model free method, 192 Kissinger method, was applied in this study. A first-order kinetics was assumed to 193 calculate the pre-exponential factor. Kissinger method assumed that the maximum heat 
flow characterizes the maximum reaction rate [15]. The basic function is Eq. (1),

$$
\ln \left(\frac{\beta}{T_{m}^{2}}\right)=\ln \left(\frac{A \mathrm{R}}{E}\right)-\frac{E}{\mathrm{R} T_{m}}
$$

where $\beta$ represents heating rate and $T_{\mathrm{m}}$ could be obtained from heat flow plot in Fig. 1,2 and 3. By plotting $\ln \left(\beta T_{\mathrm{m}}^{2}\right)$ versus $1 / T_{\mathrm{m}}$ under three heating rates and making a linear fitting, $E$ was derived by the slope. Logarithm of $A$ was calculated from the expression given in ASTM E698 [16],

$$
\mathrm{A}=\beta\left(\frac{E}{\mathrm{R} T_{m}^{2}}\right) \exp \left(\frac{E}{\mathrm{R} T_{m}}\right)
$$

To test the value, Ozawa method was used to determine $E$. Ozawa method can determine the activation energy of reactants without a precise knowledge of reaction mechanism, by using Eq. (6)[3]

$$
\log \beta+0.496\left(\frac{E}{\mathrm{R} T_{m}}\right)=\text { Constant }
$$

Similarly, plot $\log \beta$ against $1 / T_{\mathrm{m}}$ and make a linear fitting, $E$ can be derived from the slope of straight line.

Table 6 7 list the results of $E$ and $A$ for all samples calculated by Kissinger and Ozawa method. Fig. 4 6 presents the curve fitting results by two kinetic methods. The activation energy calculated by Kissinger method is relatively lower than that by Ozawa method. But both methods indicated that adding acids reduced the activation energy of NC. Lowest activation energy was calculated for the Peak 2' of NC mixed with SA, which was $58.57 \mathrm{~kJ} \mathrm{~mol}^{-1}$ by Kissing method and $57.49 \mathrm{~kJ} \mathrm{~mol}^{-1}$ by Ozawa method. The second lowest activation energy belongs to the Peak 1 in NC mixed with NA, which was $76.23 \mathrm{~kJ} \mathrm{~mol}^{-1}$ by Kissing method and $72.27 \mathrm{~kJ} \mathrm{~mol}^{-1}$ by Ozawa method. This was nearly a half lower than Peak 1' of NC mixed with SA. This indicates that NC contaminated by NA has the lowest thermal stability and requires least energy to activate decomposition process. Therefore, the thermal stability order of three samples in perspective of activation energy, $\mathrm{NC}>\mathrm{NC}$ with $\mathrm{SA}$ impurity $>\mathrm{NC}$ with $\mathrm{NA}$ impurity.

After obtaining the kinetic parameters, thermodynamic parameters of activation reaction, including free energy $\left(\Delta G^{*}\right)$, enthalpy $\left(\Delta H^{*}\right)$ and entropy $\left(\Delta S^{*}\right)$ can be derived by the Eq. (4)-(7) [14], 


$$
A \exp \frac{-E}{\mathrm{R} T}=v \exp \frac{-\Delta G^{*}}{\mathrm{R} T}
$$

$$
\Delta H^{*}=E-\mathrm{R} T
$$

$$
v=\frac{\mathrm{K}_{\mathrm{B}} T}{\mathrm{~h}}
$$

226 where $\mathrm{K}_{\mathrm{B}}$ and $\mathrm{h}$ are Boltzmann and Plant constant, respectively.

227 The thermodynamic values for all samples were calculated at peak temperature 228 from heat flow plots by C80. Results based on the kinetics are given in Table 6 and 7. 229 For all the peaks, the $\Delta G^{*}$ were close, ranging from $105.35 \mathrm{~kJ} \mathrm{~mol}^{-1}$ to $127.50 \mathrm{~kJ} \mathrm{~mol}^{-1}$. 230 The pattern of $\Delta H^{*}$ values was consisting with the activation energy among all samples, 231 with value of 55.11/54.03 $\mathrm{kJ} \mathrm{mol}^{-1}$ for Peak 2' of NC mixed with SA and 73.13/68.71 $232 \mathrm{~kJ} \mathrm{~mol}^{-1}$ for Peak 1 of NC mixed with NA. These values were much lower than other 233 peaks. For NC by Ozawa method, Peak 1 and Peak 2', negative value of $\Delta S^{*}$ was derived.

\begin{tabular}{|c|c|c|c|c|c|c|}
\hline \multirow[b]{2}{*}{ Method } & \multicolumn{3}{|c|}{ Kinetics } & \multicolumn{3}{|c|}{ Thermodynamics } \\
\hline & $\begin{array}{c}E \\
\left(\mathrm{~kJ} \mathrm{~mol}^{-1}\right)\end{array}$ & $A\left(\mathrm{~s}^{-1}\right)$ & $R^{2}$ & $\begin{array}{c}\Delta G^{*} \\
\left(\mathrm{~kJ} \mathrm{~mol}^{-1}\right)\end{array}$ & $\begin{array}{c}\Delta H^{*} \\
\left(\mathrm{Kj} \mathrm{mol}^{-1}\right)\end{array}$ & $\begin{array}{c}\Delta S^{*} \\
\left(\mathrm{~J} \mathrm{~mol}^{-1}\right)\end{array}$ \\
\hline Kissinger & 123.67 & $1.68 \times 10^{14}$ & 0.934 & 113.60 & 120.30 & 16.56 \\
\hline Ozawa & 114.24 & $9.41 \times 10^{12}$ & 0.985 & 104.17 & 110.88 & 16.56 \\
\hline
\end{tabular}

Table 6. Kinetics and thermodynamics of $\mathrm{NC}$ under a $0.2 \mathrm{~min}^{-1}$ heating rate.

Table 7. Kinetics and thermodynamics of NC mixed with NA or SA under a 0.2 $\min ^{-1}$ heating rate for Peak 1 .

\begin{tabular}{cccccccc}
\hline \multirow{2}{*}{ Sample } & & \multicolumn{3}{c}{ Kinetics } & \multicolumn{3}{c}{ Thermodynamics } \\
\cline { 3 - 7 } No. & Method & $E$ & $A$ & & $\Delta G^{*}$ & $\Delta H^{*}$ & $\Delta S^{*}$ \\
& & $\left(\mathrm{~kJ} \mathrm{~mol}^{-1}\right)$ & $\left(\mathrm{s}^{-1}\right)$ & & $\left(\mathrm{kJ} \mathrm{mol}^{-1}\right)$ & $\left(\mathrm{kJ} \mathrm{mol}^{-1}\right)$ & $\left(\mathrm{J} \mathrm{mol}^{-1}\right)$ \\
\hline \multirow{2}{*}{ NC-NA } & Kissinger & 76.23 & $6.42 \times 10^{8}$ & 0.859 & 105.35 & 73.13 & -86.46 \\
& Ozawa & 72.27 & $1.69 \times 10^{8}$ & 0.879 & 110.93 & 68.71 & -98.69 \\
& Kissinger & 127.65 & $6.72 \times 10^{14}$ & 0.956 & 112.96 & 124.30 & 28.14 \\
NC-SA & Ozawa & 117.7 & $3.18 \times 10^{13}$ & 0.962 & 113.23 & 114.35 & 2.77 \\
\hline
\end{tabular}


Table 8. Kinetics and thermodynamics of NC mixed with NA or SA under a 0.2 $\min ^{-1}$ heating rate for Peak 2 .

\begin{tabular}{cccccccc}
\hline & & \multicolumn{3}{c}{ Kinetics } & \multicolumn{3}{c}{ Thermodynamics } \\
\cline { 3 - 7 } Sample No. & Method & $E$ & $A$ & $\Delta G^{*}$ & $\Delta H^{*}$ & $\Delta S^{*}$ \\
& & $\left(\mathrm{~kJ} \mathrm{~mol}^{-1}\right)$ & $\left(\mathrm{s}^{-1}\right)$ & & $\left(\mathrm{kJ} \mathrm{mol}^{-1}\right)$ & $\left(\mathrm{kJ} \mathrm{mol}^{-1}\right)$ & $\left(\mathrm{J} \mathrm{mol}^{-1}\right)$ \\
\hline \multirow{2}{*}{ NC-NA } & Kissinger & 138.67 & $1.57 \times 10^{15}$ & 0.993 & 120.28 & 135.11 & 34.66 \\
& Ozawa & 127.71 & $6.62 \times 10^{13}$ & 0.993 & 120.57 & 124.15 & 8.36 \\
& Kissinger & 58.57 & $1.85 \times 10^{5}$ & 0.653 & 119.63 & 55.11 & -155.14 \\
NC-SA & Ozawa & 57.49 & $1.33 \times 10^{5}$ & 0.715 & 119.69 & 54.03 & -157.90 \\
\hline
\end{tabular}
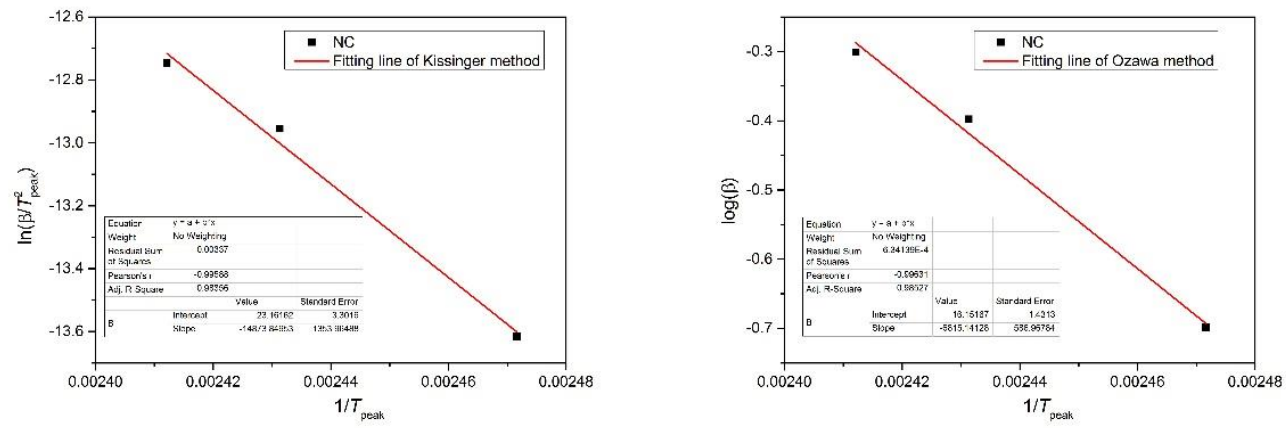

Fig. 4. Kinetics fitting results of NC by Kissinger method and Ozawa method.
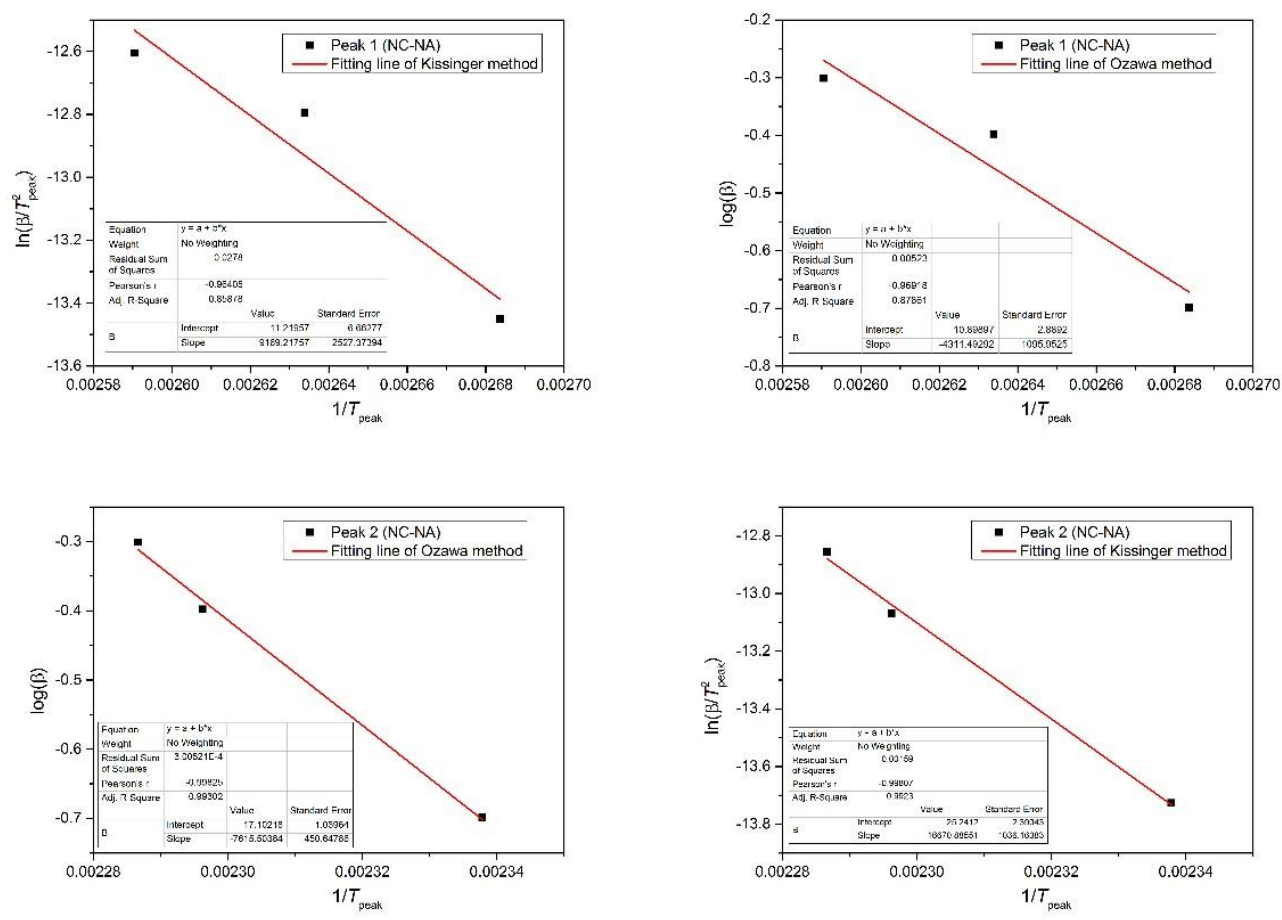

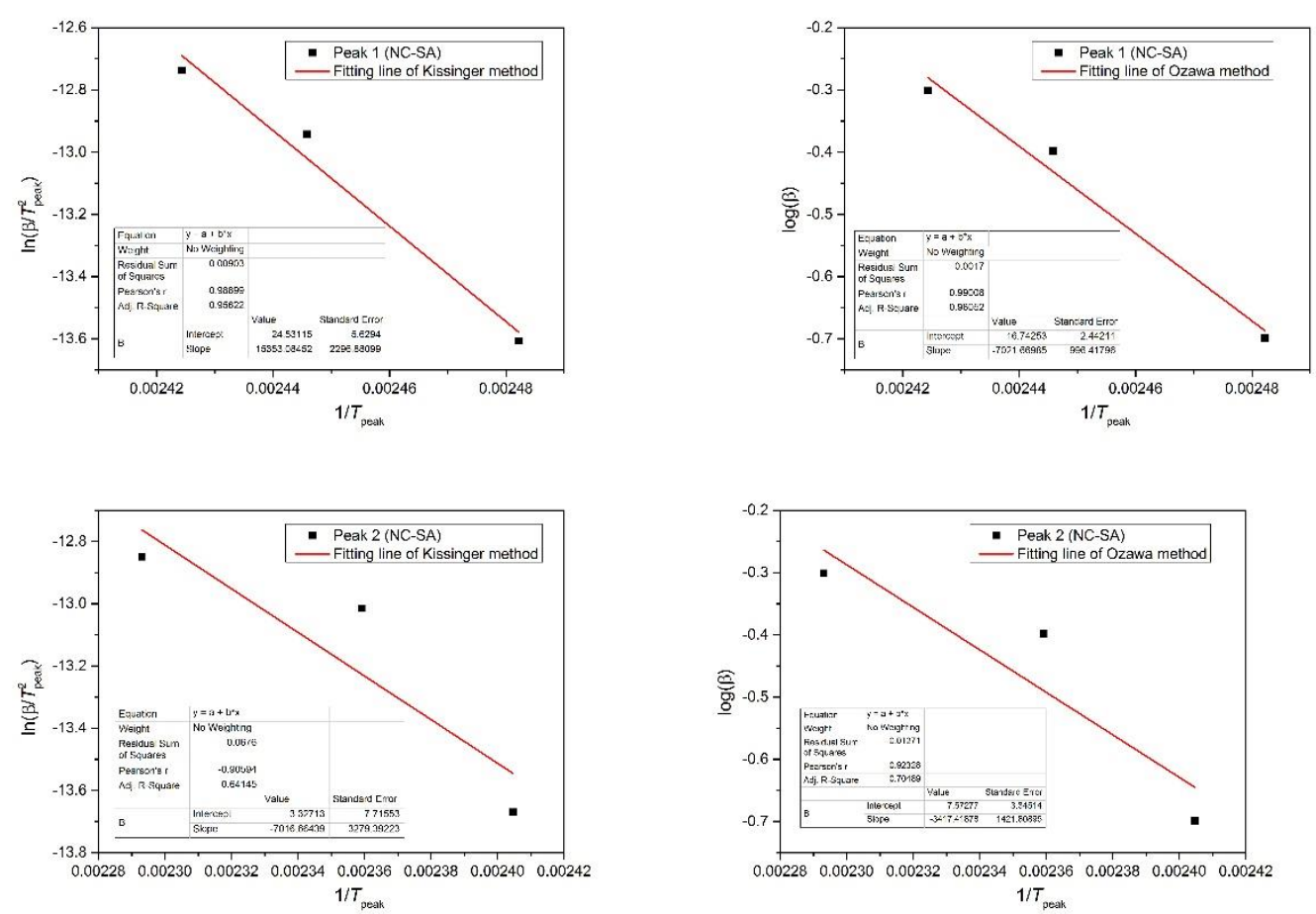

Fig. 6. Kinetics fitting results of NC mixed with SA by Kissinger method and

\subsection{Mechanism and hazards}

Based on previous literatures $[6,7,17]$, decomposition of NC starts by breaking $\mathrm{O}-\mathrm{NO}_{2}$ bond and generates oxygen free radicals, $\mathrm{CH}_{2} \mathrm{O}$ and $\mathrm{NO}_{2}$ [18]. Oxygen free radicals turn into carbonyls by transferring its electrons into carbon atom. The -O-NO bond scission is a continuous process and $\mathrm{NO}_{2}$ plays role as activation of autocatalysis reaction [19]. The-C-O-C- bonds in glucopyranosyl ring also break, and $\mathrm{CH}_{2} \mathrm{O}$ reacts with $\mathrm{NO}_{2}$ at the same time. Ultimately, various gases such as $\mathrm{CO}_{\mathrm{x}}$ and $\mathrm{NO}_{\mathrm{x}}$ are generated, see Eq. (8) and (9). Given that acids were present in NC mixed with NA and 3, acid hydrolysis was responsible for the lower stability to start the decomposition

258 process by function of $\left[\mathrm{H}^{+}\right]$. From the study of Brill and Gongwer [20], a chemical 259 equilibrium between $\left[\mathrm{H}^{+}\right]$and $\mathrm{RONO}_{2}$ occurred and generated intermediate products $260\left[\mathrm{RONO}_{2} \mathrm{H}^{+}\right]$. The secondary products liberated small amount of $\mathrm{NO}_{\mathrm{x}}$ and increase the 261 reaction rate. The form of $\left[\mathrm{RONO}_{2} \mathrm{H}^{+}\right]$due to acid hydrolysis changed the reaction 
262 process when temperate was lower than $200{ }^{\circ} \mathrm{C}$, and promoted autocatalysis reactions.

263 This principle could explain the promotion of decomposing process by two inorganic 264 acids (see Eq. (10) and (11)).

265 Despite that all the samples showed autocatalytic characteristics, NA and SA have 266 different effects on thermal decomposition of NC due to their chemical natures. There 267 are two possible reasons. Firstly, the NA and SA had the same mass fraction, indicating 268 that content of $\left[\mathrm{H}^{+}\right]$in SA was twice more than that of NA. Secondly, the differences in 269 thermal behavior of SA and NA itself may account for it. NA could easily decompose 270 under heating condition [9], so the first peak in NC mixed with NA may be caused by 271 the instability of NA itself. The process generated $\mathrm{NO}_{x}$, especially $\mathrm{NO}_{2}$, which acted as 272 catalysis to promote the thermal decomposition process. While for $\mathrm{SA}$, the $\left[\mathrm{H}^{+}\right]$played 273 major role, so the first peak contributed to most of the reaction heat. However, this is a 274 rough analysis for such a complex decomposition process. Additional experimental techniques are still required in future study to obtain a deeper understanding of possible mechanism and reaction kinetics.

$$
\mathrm{RO} \cdot+\mathrm{NO}_{2} \rightarrow \mathrm{ROO} \cdot+\mathrm{NO}
$$

$$
\mathrm{ROO} \cdot+\mathrm{NO} \cdot \rightarrow \mathrm{RO} \cdot+\mathrm{NO}_{2} / \mathrm{RONO}_{2}
$$

$$
\mathrm{RONO}_{2}+\mathrm{H}^{+} \rightleftharpoons \mathrm{RONO}_{2} \mathrm{H}^{+}
$$

$$
\mathrm{RONO}_{2} \mathrm{H}^{+} \rightarrow \mathrm{ROH}+\mathrm{NO}_{2}^{+}
$$

Comparing with $\mathrm{NC}$ in high nitrogen content and applied for explosives, the sample in this study is relatively safer and commonly applied in chemical industry. However, the experiments by $\mathrm{C} 80$ identified that, not only does $\mathrm{NC}$ itself has high possibility to occur autocatalytic decomposition, contamination by NA and SA could greatly reduce its thermal stability by reducing onset temperature and generate large amount of heat in a very short time region. Particularly, SA could dramatically increase thermal hazards of NC once the decomposing starts. Therefore, much attention should be paid to during manufacturing, storage, processing, and transportation of NC.

\section{Conclusions}

The thermal decomposition characteristics and heat generation of pure NC, and its 
291 mixture with NA and SA were researched using a C80 calorimeter. Two temperature 292 models, constant heating under $0.2,0.4$ and $0.5{ }^{\circ} \mathrm{C} \mathrm{min} \mathrm{m}^{-1}$ heating rate and isothermal 293 heating were applied. Characteristics of heat flow plots in various heating rate were 294 analyzed. The autocatalytic mechanism was identified by reaction curve analysis and 295 isothermal experiments. Kinetics and thermodynamics were obtained by two model 296 free kinetic methods. The effect of acids on thermal decomposition of NC were 297 analyzed. Major conclusions were obtained as follows.

298 (1) Both contamination of NA and SA promoted the thermal decomposition process 299 of NC, reduced the onset temperature, and shorten the temperature region. SA had more 300 significant influence on thermal decomposition of NC than NA in perspective of 301 maximum heat flow, heat generation and temperature region. Mixture of NC with NA 302 has the lowest initial temperature value of $62.53{ }^{\circ} \mathrm{C}$.

303 (2) The catalytic mechanism was proved by both reaction curve analysis and 304 isothermal experiment methods. Bell-shape curves were identified in all samples. The 305 decomposition of pure NC and NC contaminated by two acids followed autocatalytic 306 mechanism and generated large amount of heat. For pure NC and NC contaminated by 307 SA, the heat generation during isothermal stage was very close to constant heating condition. Decomposition almost finished during isothermal heating condition.

(3) Kissinger method and Ozawa method were applied to calculated kinetics of pure NC and its mixture with two acids. Thermodynamic parameters were derived 311 based on peak temperature of heat flow. Activation energy value by Ozawa method was 312 smaller than Kissinger method. But two methods reflected the consistent results that, 313 adding acids reduced the activation energy, and NC contaminated by NA had the lowest 314 activation energy value to start thermal decomposition, which was $76.23{ }^{\circ} \mathrm{C}$ by 315 Kissinger method and $72.27^{\circ} \mathrm{C}$ by Ozawa method.

316 (4) The chemical equilibrium between $\left[\mathrm{H}^{+}\right]$and $\mathrm{RONO}_{2}$ generated intermediate 317 products $\left[\mathrm{RONO}_{2} \mathrm{H}^{+}\right]$, which decomposed into small amount of $\mathrm{NO}_{\mathrm{x}}$ and increased the 318 reaction rate. The mechanism for NA and SA to influence NC's decomposition was 319 different. The differences in thermal decomposition of pure NA and SA itself accounted 320 for such different effects. 


\begin{tabular}{|ll|}
\hline A & pre-exponential factor $\left(\mathrm{s}^{-1}\right)$ \\
ARC & accelerating rate calorimeter \\
$\mathrm{C} 80$ & C80 micro calorimeter \\
$E$ & activation energy $\left(\mathrm{J} \mathrm{mol}{ }^{-1}\right)$ \\
$\Delta G^{*}$ & free energy $(\mathrm{kJ}$ mol-1) \\
$\mathrm{h}$ & plank constant \\
$\Delta H^{*}$ & free enthalpy $(\mathrm{kJ}$ mol-1) \\
$\Delta H$ & reaction heat $\left(\mathrm{J} \mathrm{g} \mathrm{g}^{-1}\right)$ \\
$\Delta H_{\text {iso }}$ & reaction heat for isothermal experiment $\left(\mathrm{J} \mathrm{g}^{-1}\right)$ \\
$H_{m}$ & peak heat flow $\left(\mathrm{mW} \mathrm{g}^{-1}\right)$ \\
$\mathrm{K}_{\mathrm{B}}$ & boltzmann constant \\
$N C$ & nitrocellulose \\
$\Delta S^{*}$ & free entropy $\left(\mathrm{J}\right.$ mol $\left.{ }^{-1} \mathrm{~K}^{-1}\right)$ \\
$T_{\mathrm{on}}$ & onset temperature $\left({ }^{\circ} \mathrm{C}\right)$ \\
$T_{\mathrm{m}}$ & peak temperature $\left({ }^{\circ} \mathrm{C}\right)$ \\
$\Delta T$ & reaction temperature region $\left({ }^{\circ} \mathrm{C}\right)$ \\
$\Delta T_{\mathrm{m}}$ & Reaction temperature region to reach $T_{\mathrm{m}}\left({ }^{\circ} \mathrm{C}\right)$ \\
\hline
\end{tabular}

\section{Acknowledgement}

This research was supported by the Open Fund of Collaborative Innovation Center 324 of Coastal Urban Rail Transit, Ningbo University \#432101753 (Research on the 325 evaluation of key technology innovation level and social and economic benefit of urban 326 rail transit machinery connection Channel). The authors gratefully acknowledge the 327 financial support.

328 References

329 [1] C.-P. Lin, Y.-M. Chang, J.P. Gupta, C.-M. Shu, Comparisons of TGA and DSC 330 approaches to evaluate nitrocellulose thermal degradation energy and stabilizer 331 efficiencies, Process Safety and Environmental Protection, 88 (2010) 413-419. 
332 [2] M.Á.F. de la Ossa, M. López-López, M. Torre, C. García-Ruiz, Analytical 333 techniques in the study of highly-nitrated nitrocellulose, TrAC Trends in Analytical 334 Chemistry, 30 (2011) 1740-1755.

335 [3] S. Pourmortazavi, S. Hosseini, M. Rahimi-Nasrabadi, S. Hajimirsadeghi, H. 336 Momenian, Effect of nitrate content on thermal decomposition of nitrocellulose, J. 337 Hazard. Mater., 162 (2009) 1141-1144.

338 [4] J.-L. Gustin, Influence of trace impurities on chemical reaction hazards, Journal of 339 Loss Prevention in the Process Industries, 15 (2002) 37-48.

340 [5] L. Dauerman, Y. Tajima, Thermal decomposition and combustion of nitrocellulose, 341 Aiaa Journal, 6 (1968) 1468-1473.

342 [6] M. Jin, N. Luo, G. Li, Y. Luo, The thermal decomposition mechanism of 343 nitrocellulose aerogel, Journal of Thermal Analysis and Calorimetry, 121 (2015) 901344908.

345 [7] A. Nada, M.L. Hassan, Thermal behavior of cellulose and some cellulose derivatives, 346 Polymer Degradation and Stability, 67 (2000) 111-115.

347 [8] K. Katoh, E. Higashi, T. Saburi, S. Ito, Y. Wada, S. Kawaguchi, K. Kumagae, M. 348 Arai, Spontaneous Ignition Behavior of Nitrocellulose-Sulfuric Acid Mixtures, in: 349 Applied Mechanics and Materials, Trans Tech Publ, 2014, pp. 280-284.

350 [9] Q. Sun, L. Jiang, L. Gong, J.-H. Sun, Experimental study on thermal hazard of 351 tributyl phosphate-nitric acid mixtures using micro calorimeter technique, Journal of 352 hazardous materials, 314 (2016) 230-236.

353 [10] M. Wagner, G. Widmann, Thermal analysis in practice, Mettler-Toledo, 2009.

354 [11] X. Zhao, Q. Wang, H. Xiao, Z. Mao, P. Chen, J. Sun, Prediction of coal stockpile 355 autoignition delay time using micro-calorimeter technique, Fuel processing technology, $356110(2013) 86-93$.

357 [12] S. Vyazovkin, A.K. Burnham, J.M. Criado, L.A. Pérez-Maqueda, C. Popescu, N. 358 Sbirrazzuoli, ICTAC Kinetics Committee recommendations for performing kinetic 359 computations on thermal analysis data, Thermochimica Acta, 520 (2011) 1-19.

360 [13] M. Keenan, Autocatalytic cure kinetics from DSC measurements: zero initial cure 361 rate, Journal of applied polymer science, 33 (1987) 1725-1734. 
362 [14] A.T. Lorenzo, M.L. Arnal, J. Albuerne, A.J. Müller, DSC isothermal polymer 363 crystallization kinetics measurements and the use of the Avrami equation to fit the data: 364 guidelines to avoid common problems, Polymer testing, 26 (2007) 222-231.

365 [15] M. Shamsipur, S.M. Pourmortazavi, S.S. Hajimirsadeghi, S.M. Atifeh, Effect of 366 functional group on thermal stability of cellulose derivative energetic polymers, Fuel, $36795(2012) 394-399$.

368 [16] E. ASTM, 698-05 Standard Test Method for Arrhenius Kinetic Constants for 369 Thermally Unstable Materials Using Differential Scanning Calorimetry and the Flynn, 370 Wall/Ozawa Method, (2005).

371 [17] M. Wolfrom, J. Frazer, L. Kuhn, E. Dickey, S. Olin, R. Bower, G. Maher, J. 372 Murdock, A. Chaney, E. Carpenter, The Controlled Thermal Decomposition of 373 Cellulose Nitrate. II1, 2, J. Am. Chem. Soc., 78 (1956) 4695-4704.

374 [18] P. Makashir, R. Mahajan, J. Agrawal, Studies on kinetics and mechanism of initial 375 thermal decomposition of nitrocellulose: isothermal and non-isothermal techniques, 376 Journal of Thermal Analysis and Calorimetry, 45 (1995) 501-509.

377 [19] F. Shafizadeh, M. Wolfrom, The Controlled Thermal Decomposition of Cellulose 378 Nitrate. IV. C14-Tracer Experiments1, 2, J. Am. Chem. Soc., 80 (1958) 1675-1677.

379 [20] T. Brill, P. Gongwer, Thermal decomposition of energetic materials 69. Analysis 380 of the kinetics of nitrocellulose at $50 \mathrm{C}-500 \mathrm{C}$, Propellants, explosives, pyrotechnics, 38122 (1997) 38-44. 